\title{
Às margens da cidade e fora do cânone: exclusão social e literária nas crónicas de Irene Lisboa
}

JeSsiCa FALCONI
Universidade de Nápoles

RESUMO: NESTE ARTIGO PRETENDO ABORDAR A RELAÇÃO ENTRE GÉNERO LITERÁRIO E O OBJECTO DA REPRESENTAÇÃO NA ESCRITA DE IRENE LISBOA. MAIS ESPECIFICAMENTE, PRETENDO DEMONSTRAR QUE O USO DA CRÓNICA, ISTO É, DE UM GÉNERO LITERÁRIO NÃO CANÓNICO, ALIADO À REPRESENTAÇÃO DO ESPAÇO URBANO, TEM A VER COM A REPRESENTAÇÃO DA EXCLUSÃO SOCIAL E COM UMA TENTATIVA DE "REVOLTA" CONTRA ESSA MESMA EXCLUSÃO. NESSA PERSPECTIVA, A AUTORA CONSTRÓI COM AS CRÓNICAS UM JOGO DE ESPELHOS, UMA MISE EN ÂBIME, NO QUAL ALGUNS GÉNEROS TEXTUAIS À MARGEM DO CÂNONE LITERÁRIO SE TORNAM VEÍCULOS EXPRESSIVOS DA MARGINALIDADE SOCIAL DAS PERSONAGENS E DA EXCLUSÃO DA PRÓPRIA AUTORA ENQUANTO ESCRITORA-MULHER.

ABSTRACT: THE PURPOSE OF MY ARTICLE IS TO BRING UP A REFLECTION ON THE RELATIONSHIP BETWEEN LITERARY GENRE AND THE SUBJECT OF THE REPRESENTATION IN IRENE LISBOA'S WORK. MORE SPECIFICALLY, MY GOAL IS TO SHOW THAT THE USE OF THE CHRONICLE - THAT IS A LITERARY GENRE OUT FROM THE MAINSTREAM - IN THE DESCRIPTION OF THE URBAN SPACE BECOMES THE REPRESENTATION OF SOCIAL EXCLUSION AND A WAY TO REACT AGAINST IT. ACCORDING TO THIS POINT OF VIEW, THE AUTHOR BUILDS THROUGH THE CHRONICLES A MIRROR SYMMETRY, A SORT OF MISE EN ÂBIME. SHE USES THESE TEXTUAL GENRES CONSIDERED "BORDER LINE", AND TO FOCUS ON THE SOCIAL MARGINALITY OF THE CHARACTERS AND OF HERSELF AS A WOMAN.

PALAVRAS-CHAVE: CIDADE - CÂNONE - MARGINALIDADE - PERIFERIA - EXCLUSÃO - CRÓNICA

KEY-WORDS: CITY - CANON - MARGINALITY - PERIPHERY - EXCLUSION - CHRONICLE 
Contar não é o meu forte. Isto de contar... Atrapalho-me, esqueco-me, ponho-me a rir, e às vezes até a chorar por dentro, sem mesmo querer. Não levo a cabo, jamais levarei a cabo, sem desfalecimentos, qualquer história. Da minha vida ou da alheia.

Irene Lisboa - Título qualquer serve

cidade e o cânone, elementos estruturadores da noção de "centro", são, paralelamente, objectos do olhar e da reflexão de Irene Lisboa, escritora durante muito tempo esquecida pelo cânone literário português ${ }^{1}$.

Aparecem, de facto, nos três volumes de crónicas da autora ${ }^{2}$, esses dois fios paralelos que, ao se entrelaçarem, criam como que uma urdidura simbólica cujo centro acaba por ser a imagem da exclusão que, segundo Beatriz Rezende, "toma seus contornos mais nítidos quando a pobreza define o papel do homem [...] em suas limitações como sujeito de direitos e responsabilidades, mas, sobretudo, como sujeito de seu próprio discurso" (REZENDE, 1999). Se, como afirma ainda Beatriz Rezende, "o reconhecimento da exclusão, o 'dizer', o 'nomear' o excluído é um primeiro passo do contrapor-se a qualquer exclusão", o carácter de contraposição à exclusão das crónicas de Irene Lisboa é bem evidente. Pretendo ainda demonstrar que as crónicas, ao serem construídas à volta dessa noção da exclusão e ao funcionarem como actos de "revolta" contra ela, acabam por ser um jogo de espelhos em que alguns géneros textuais à margem do cânone literário se tornam veículos expressivos da marginalidade social das personagens e da exclusão da própria autora enquanto escritora-mulher, numa época em que o acesso das mulheres à literatura é ainda extremamente problemático.

Sugere-me essa hipótese a reflexão de Ana Paula Ferreira sobre o facto de as escritoras portuguesas dos anos 1940 privilegiarem o género do conto. O conto, argumenta a autora, cujo funcionamento radica "na constante tensão entre His-

1 A partir dos anos 1990, o trabalho crítico e editorial da professora Paula Morão, os artigos de Ellen Sapega, Ana Paula Ferreira, Ana Luísa Amaral, entre outros, têm vindo a devolver à obra de Irene Lisboa o lugar que merece na história da Literatura Portuguesa.

2 Refiro-me a Esta cidade!, de 1942, O pouco e o muito - crónica urbana, de 1956, e Título qualquer serve, de 1958. As citações são retiradas das edições da Editorial Presença. 
tória e estória", isto é, entre um plano exemplar e um plano individual, acabaria por ser, na prosa narrativa dessa década, um género estratégico para as mulheres na medida em que possibilita "a amplificação dramática da experiência individual e local através do seu enquadramento narrativo" (FERREIRA, 1999).

No que diz respeito à obra de Irene Lisboa, temos de acrescentar ao conto outros géneros textuais que com ele partilham o carácter imediato, por vezes impressionista. Trata-se da crónica, do "apontamento", da "nota", ou seja, formas de narrar fragmentárias e aparentemente inacabadas. Várias têm sido as interpretações dessa opção, a maior parte das quais apontando para uma exigência de "verdade" (muitas vezes reiterada pela própria autora) como razão principal da escolha de géneros supostamente menos ficcionais do que o romance ${ }^{3}$. Na verdade, sobre a eficácia desses géneros textuais e sua legitimidade, reflecte a própria Irene Lisboa ao longo de toda a sua obra, ficcionalizando a própria reflexão sobre a narrativa, em que encontramos traços dum diálogo nem sempre pacífico com o cânone.

Na introdução a Esta cidade!, primeira colectânea de crónicas, Irene Lisboa aborda de imediato a questão do género, declarando abertamente que não quis "cultivar a novela nem o romance" (LISBOA, 1995: 16). Na hora de definir o género literário dos seus textos, a autora utiliza deliberadamente perífrases e expressões que se opõem, por extensão, aos curtos rótulos identificadores dos géneros canónicos, e tornam patente o trabalho ficcional levado a cabo sobre a matéria, "casos" da vida postos "em letra redonda", "reduzidos a estilo" e que, de facto, a própria autora não sabe como há de definir. Essa mesma reflexão, presente em todos os textos de sua autoria, no caso das crónicas acaba por dar, juntamente com os temas explorados, uma certa unidade e continuidade a textos escritos durante um lapso temporal bastante amplo. É por isso que podemos considerar os três volumes de crónicas como um conjunto temático e formal, com bem esclarece também Paula Morão.

A abertura de Esta cidade! introduz de imediato o leitor na matéria narrativa escolhida: "casos e criaturas" que a autora observou e que decidiu "simples-

3 Embora as intenções fossem positivas, essas interpretações correm o risco de reforçar, por um lado, o preconceito duma "literatura feminina" ligada a géneros textuais em aparência mais espontâneos e naturais; por outro lado, de retirar qualidade estética à obra de Irene Lisboa, confirmando, assim, a sua exclusão do cânone. Coube ao trabalho rigoroso de Paula Morão desvendar os mecanismos ficcionais tanto das narrativas autobiográficas e de cariz intimista como das crónicas urbanas. 
mente" contar; entramos, portanto, no universo do comum, do banal, do quotidiano, e é na relação entre a questão do género e esse universo que Irene Lisboa irá insistir em vários pontos das suas obras. Na memorável crónica intitulada "A Adelina", dividida em três partes (quase como que um folhetim), a autora confessa que "a verdadeira Adelina, a de carne e osso, é uma pobre criatura cuja vida não dá um romance" (LISBOA, 1995: 122), abordando assim a questão da representação literária da pobreza e da marginalidade, aliada àquela da banalidade e do quotidiano, e sugerindo como que uma "incompatibilidade" entre os géneros literários canónicos e essa mesma representação.

Com efeito, se nas crónicas encontramos representantes de todas as classes sociais, a presença dos marginais, dos excluídos é proeminente: a Adelina, uma mulher-a-dias mergulhada num quotidiano de miséria, abre, de facto, a galeria de personagens anónimas, "sem história", que povoam a Lisboa de quase duas décadas, cujo mapa humano e moral as crónicas de Irene Lisboa tratam de recompor. Trata-se de indivíduos que exercem profissões humildes, "saloios" vindos para a cidade e que não conseguem integrar-se no labirinto da (suposta) modernidade, até crianças, cuja infância, marcada pela pobreza, parece anunciar um destino já escrito.

É a essas criaturas, excluídas "do seu próprio discurso", que a autora tenta dar voz contando as suas histórias ou, como no caso da crónica intitulada "Vida", cedendo-lhes inteiramente a palavra. Nessa crónica aparece, logo a seguir ao título, entre parêntesis, a palavra "atribuição"; de facto, o texto apresenta-se como uma carta escrita pela própria personagem. Seja qual for a verdadeira origem do texto, o que aqui interessa é a apropriação do discurso por parte dum sujeito marginal, cuja marginalidade é dada por vários elementos. Trata-se de um rapaz de 14 anos que deixa a aldeia de origem aos nove anos para ir trabalhar na capital. Sozinho e afastado da família (o destinatário da carta é a mãe), Evaristo conta, com a linguagem e o olhar da sua idade, a experiência na grande cidade. Lisboa aparece-lhe como um imenso parque de atracções, aproximando-se do paradigma da cidade do romance oitocentista, ou seja, o símbolo de uma sociedade legitimadora das aspirações individuais, cidade prometedora de infinitas possibilidades (ILARDI, 2005: 59). Ao mesmo tempo, é o lugar da solidão, do frio, das saudades da vida na aldeia e, sobretudo, das desilusões, visto as aspirações do jovem terem fracassado: "Hoje estou um homem, mas não ganho vintém” (LISBOA, 1996: 72), diz Evaristo 
na carta dirigida à mãe, em que se torna patente toda espécie de desamparo a que está sujeita uma criança chegada à cidade, sem família e sem esperança de progressão social. O que ainda ressalta na crónica é mais uma condição de exclusão de que padece Evaristo: toda a comunicação com a mãe se desenvolve apenas num plano imaginário, mental, irreal. As cartas que Evaristo escreve nunca serão entregues, porque são fruto do pensamento de um sujeito que se encontra até desprovido da possibilidade de se comunicar com o seu mundo familiar. A crónica acaba por representar, de facto, o único lugar textual a que Evaristo tem direito e acesso.

Lisboa é o cenário do desamparo também para outra criança, Maria José, "Rapariguinha da rua", "uma espécie de boneca de trapos da cidade!", que acompanha a cronista do Largo do Rato ao Bairro Alto, através de umas ruas "tão cheias [...] de todo o ranço da velha vida obscena da cidade!" (LISBOA, 1995: 175). Também Maria José é, de alguma maneira, defraudada de um discurso próprio, desprovida da linguagem que deveria usar enquanto criança. Acostumada às dificuldades do dia-a-dia, à pobreza, ao "câncaro" da mãe, Maria José já não se expressa como uma criança, antes, repete os discursos e as palavras dos adultos; de facto, a cronista comenta: "O que se via é que a linguagem da rapariguinha andava toda à roda da miséria fria da sua família sem sorte".

Essa perda do direito ao discurso, à linguagem, à expressão é o traço de uma personagem inesquecível da crónica mais urbana de Irene Lisboa: tratase de uma mulher anónima que aparece no elevador do Lavra, lugar de trânsito da população que a cronista escolhe para as suas observações de "casos e criaturas". Uma mulher de que não sabemos nada, símbolo da exclusão absoluta, de um destino sem redenção, "uma destas mulheres esgrouviadas, sem raça nem era e ainda nova, que o mundo parece cuspir de si" (LISBOA, 1995: 106).

Entre a vida da Adelina, mulher de idade já avançada, e aquela do Evaristo, ou da pequena Maria José, que tem apenas 10 anos, do Gregório Máximo, pobre e velho, que se enforca sem que ninguém dê por isso, ou ainda da mulher que entra no elevador, acaba por não haver muita diferença: a vida de todos passa-se através dos itinerários urbanos da pobreza, da solidão e da exclusão social.

Muitas vezes identificáveis, esses itinerários mostram de maneira inequívoca, como sugere Beatriz Rezende, que a condição de excluído aparece em relação com o espaço, "seja o espaço da cidade real, seja o espaço imaginário 
da literatura" (1999). Nos bairros descritos nas crónicas de Irene Lisboa, a descontinuidade arquitectónica assinala e significa a descontinuidade social. O espaço é, portanto, inteiramente modelado pelas hierarquias das classes sociais. É o caso da "A cabrilha", em que a descrição de um bairro em obras nos oferece o retrato de dois mundos, física e socialmente separados por aquilo que Kevin Lynch chamaria de barreira artificial (LYNCH, 1985: 67), isto é, um elemento que interrompe a continuidade. Essa barreira, "aquelas grades, em forma de ganchos", serve de facto para separar os "doutores" e as suas vivendas da "gentinha das barracas [...] considerada medonha pelo guarda das boas propriedades" (LISBOA, 1996). A barreira em questão é, portanto, simultaneamente uma fronteira arquitectónica e social, e a descontinuidade do espaço é o resultado da vontade humana, uma espécie de planificação ambiental que visa evidenciar as diferenças sociais e económicas.

Ao lermos as crónicas de Irene Lisboa, reparamos no facto de essas descontinuidades serem o traço característico da cidade; com efeito, em "Modistas de chapéu", a descrição do bairro nos devolve outra vez uma situação em que, apesar de uma aparente contiguidade, as separações entre as classes sociais acabam por ser sempre marcadas fisicamente por diferenças visíveis: "É um bairro de miséria e aristocracia (há nele muitos palácios e jardins alternando com gaiolas de pobres) [...]. Tem ruas de um isolamento admirável, de parque, e cantos ou espaços mesmo em linha recta de uma piolhagem afrontosa" (LISBOA, 1995: 122).

A descrição da exclusão encontra um ponto máximo na crónica intitulada "Naquele domingo", em que a cidade de Lisboa é perfeitamente reconhecível através de algumas referências; o olhar da cronista identifica outro tipo de barreira, uma barreira natural entre "mundos sobrepostos, entre si ignorados...": por debaixo da auto-estrada, nas fendas duma rocha, vive, em condições de absoluta degradação, toda uma população de excluídos. "Encostados ali à rocha aqueles rebotalhos da sociedade, irremediavelmente desmoralizados, famintos e sem esperança", vivem a pouca distância da modernidade, do suposto progresso, da "luz, a liberdade, os regalos, a elegância, os desperdícios da vida" (LISBOA, 1996: 121). A cidade descrita por Irene Lisboa acaba por ser, muitas vezes, como uma das "Cidades Invisíveis" de Ítalo Calvino, Moriana, que "consiste solo in un diritto e in un rovescio, come un foglio di carta, con una figura di qua e una di là, che non possono staccarsi né guar- 
darsi" (CALVINO, 1993: 105). Nessa crónica, mais do que o género literário, Irene Lisboa põe retoricamente em discussão a própria possibilidade de descrever, de nomear a realidade de degradação a que assiste: "Poderes da reprodução, da tradução expressiva, intencional, não me socorreis, bem o sinto..." (LISBOA, 1996: 116).

Nas crónicas citadas a miséria, a degradação e a exclusão social são elementos de descontinuidade enquanto em contraposição ao bem-estar das classes burguesas; noutras crónicas, como "A enfermeira", a exclusão apresenta-se como a dimensão proeminente da vida urbana, uma linha contínua sem interrupções. $\mathrm{E}$, de uma maneira geral, como uma característica da cidade moderna: "Sempre a mesma coisa, comum talvez a todas as grandes cidades: Paris, Londres, Xangai, Rio... Miséria espectaculosa e miséria escondida; em poços, em abomináveis cisternas da vida ou estateladas ao sol e às moscas" (LISBOA, 1996: 70). A protagonista cumpre, de facto, uma viagem quotidiana através do inferno urbano, à descoberta do "subsolo" social e moral da cidade: "Mas que opressivo banho de miséria tomava em cada manhã! [...] toda a confusão, toda a soma de desgraças que se lhe patenteavam. Em cada buraco que visitava imperava um tipo de vida, sórdido quase sempre" (LISBOA, 1996: 71).

É através da descrição, da "tradução expressiva" do olhar que se leva a cabo uma profunda crítica à sociedade portuguesa daquela altura. Se é verdade que nas crónicas de Irene Lisboa nunca encontramos referências explícitas à ditadura fascista, podemos, porém, como bem repara Ellen Sapega, ler nesses textos "uma vontade de contestar a imagem optimista da sociedade portuguesa disseminada pela máquina propagandística do Estado salazarista" (1996: 100). De facto, se compararmos o retrato da vida urbana que emerge nas crónicas de Irene Lisboa com os discursos oficiais do Estado Novo sobre a "missão civilizadora" de Portugal, a retórica do optimismo quanto à recuperação do glorioso passado nacional ou com as iniciativas que visavam reforçar o sentimento de unidade nacional, tal como a exposição do Mundo Português de 1940, torna-se evidente o contraste de visões. Longe de qualquer noção de "unidade", as crónicas, pelo contrário, retratam um país profundamente fragmentado, de que a exclusão social parece ser elemento estruturador e em que a única possível "unidade" é aquela da miséria.

Não deixa de surpreender, por um lado, o facto de as crónicas terem escapado à censura. Se por um lado podemos concordar com Morão e Sapega 
quando afirmam que isso foi possível pelo facto de a autora criticar o regime de maneira extremamente velada, por outro lado a citada reflexão de Ana Paula Ferreira aponta para uma explicação de carácter diferente. O cultivo de alguns géneros textuais acaba por ser uma escolha instrumental: podemos muito bem imaginar, de facto, o desinteresse e a falta de consideração por textos não só pertencentes a géneros literários marginais, mas também (e sobretudo) escritos por mulheres, isto é, pela dita "literatura feminina".

A questão do cânone literário e da presença das mulheres na literatura é um assunto fundamental das crónicas urbanas. O próprio facto de a autora inserir entre as histórias de personagens que vivem às margens da sociedade outras tantas que relatam as dificuldades das mulheres em encontrar um lugar no mundo literário e no cânone, cria uma dimensão comum, um território de partilha da condição e do sentimento da exclusão.

Em Esta cidade! ao pé da Adelina encontramos uma personagem que poderia perfeitamente funcionar como alter ego da narradora; trata-se de Helma, mulher alemã emigrada para Portugal, onde leva uma vida muito de "pária", isto é, de excluída, apesar das suas qualidades intelectuais invulgares. Através da situação da Helma, a autora parece descrever a sua própria posição no meio cultural português: "Não era ela nossa hóspeda, autora sem público, professora sem cátedra, intelectual sem meio?" (LISBOA, 1995: 53); e é também significativo o facto de a narradora escolher uma estrangeira, uma espécie de exilada, para sugerir uma possível identificação. Para além da representação autobiográfica, o que interessa é a reconstrução de um clima cultural e de um meio literário fechado e hipócrita em que as poucas mulheres que conseguem entrar produzem uma literatura de escassa qualidade que a narradora critica duramente noutra crónica, intitulada "Um dito": "Em Portugal a literatura não tinha cor nem carácter [...] As [mulheres] que se inclinavam para as letras faziam contos morais para bebés [...] Comparando os livros que saíram da pena de mulheres por essa época com os de hoje somos forçados a apreciar aqueles. $\mathrm{O}$ espírito das actuais moralistas, amadoras de letras, impõe à juventude e não já à infância um estilo celular, apesar de adocicado, indigerível e absolutamente estúpido. De sacristia, como antes se chamava" (LISBOA, 1995: 220-221).

Na crónica citada, a narradora conta a história de Sara, que se desenvolve numa época anterior ao plano temporal em que se coloca a narradora. Mais 
do que a história, o que chama a atenção são os comentários sobre o meio literário e a luta para entrar no cânone, que poderiam com muita probabilidade estar referidos também à contemporaneidade da autora: "Este agora era o tempo das polémicas literárias terrivelmente violentas, que enchiam jornais e ocupavam os homens, como se um lugar no arraial das letras pudesse mudar a face do mundo" (LISBOA, 1995: 223). Essa crítica do meio literário volta noutra crónica em que, através do curto relato de um episódio, podemos ler claramente a interligação entre a questão do cânone e do género literário e a representação da marginalidade. Trata-se de "Fazer novelas", em que a personagem é uma escritora que de vez em quando colabora com uma revista escrevendo "uns artigos ligeiros, como ela pretendia" (LISBOA, 1996: 205). A certa altura, a escritora decide propor à directora da revista uma reportagem: "Ideia não original, sem dúvida. A originalidade, aliás, é tão relativa!", diz a própria narradora, e não podemos deixar de ler nesse comentário uma referência velada à estética da Presença, ao manifesto presencista de José Régio, cujo mote era mesmo a originalidade em literatura, o estilo próprio.

$\mathrm{O}$ assunto que a escritora propõe para a sua reportagem é a vida dos trabalhadores das minas de volfrâmio, ou seja, um assunto de que já se falava em todos os jornais, porque alguns dos trabalhadores tinham morrido. O que a escritora quer fazer, na realidade, mais do que uma reportagem tradicional, é ir "em busca de sensações filhas do volfrâmio [...] imaginando, com poucos dados e simples fantasia o que seriam aquelas vidas, que corriam em tropel pelas nossas minas, aldeias e estradas" (LISBOA, 1996: 206). É evidente que o que a personagem designa como reportagens é, na realidade, algo muito parecido com as próprias crónicas de Irene Lisboa, isto é, textos de ficção cuja matéria muitas vezes provém da observação "realista" do mundo, da sociedade, da realidade. É claro também que a autora está aqui a questionar os géneros literários e, de alguma maneira, a explicitar as suas opções, a sua estética. O que confirma essa leitura é também a resposta da directora: "É melhor fazer novelas, o assunto presta-se", resposta que de facto expressa, por um lado, o pensamento da autora acerca da questão dos géneros e, por outro lado, o pensamento comum do meio cultural daquela altura. Isto é, na hierarquia dos géneros, cabe à novela e ao romance o estatuto de obra de ficção, portanto, obra de arte, enquanto o que a narradora designa como reportagem, ou seja, género textual híbrido, se quisermos, fica à margem da 
literatura, do cânone. O desfecho da crónica reforça a condição de exclusão do cânone de que a autora/narradora é vítima: "As novelas lêem-se sempre", diz a directora, tacitamente recusando a proposta da protagonista. Em "A dívida", essa polémica com o cânone e com a "ditadura" dos géneros toma o tom do desabafo autobiográfico, com a única distância emocional criada pelo uso da narração em terceira pessoa, e quase que desemboca numa polémica contra a própria existência dos géneros literários: "A rapariga tinha feito um livro de versos, de versos ou de contos; de contos ou versos... um livro sem género" (LISBOA, 1996: 175).

Essas personagens (e não é uma casualidade o facto de serem todas mulheres) padecem, de alguma maneira, a mesma falta de direito à expressão, a um discurso próprio, que sofrem as personagens como o Evaristo, a rapariguinha da rua, a mulher anónima. Podemos, portanto, concluir que nas crónicas urbanas de Irene Lisboa há uma conformidade entre o "objecto" da representação e a própria representação: o objecto, isto é, o excluído pela sociedade, o que vive à margem da vida urbana, é representado através de um género literário e por um sujeito ambos “excluídos” do cânone. Estamos perante, portanto, uma dupla periferia e uma dupla perifericidade: às margens da cidade, fora do cânone.

\section{Referências Bibliográficas}

CALVINO, Italo. Le città invisibili. Milano: Mondatori, 1993.

FERREIRA, Ana Paula. A urgência de contar: anos quarenta, casos de mulheres. Disponível em: <http://victorian.fortunecity.com/statue/44/ail.html>.

ILARDI, Emiliano. Il senso della posizione. Roma: Meltemi, 2005.

LISBOA, Irene. Titulo qualquer serve. Lisboa: Presença, 1998. - O pouco e o muito. Lisboa: Presença, 1996. . Esta cidade! Lisboa: Presença, 1995.

LYNCH, Kevin. L'immagine della città. Venezia: Marsilio Editori, 1985.

REZENDE, Beatriz. Imagens da exclusão. Disponível em: <http://victorian.fortunecity.com/statue/44/zimagensdaexclusao.htm>.

SAPEGA, Ellen. Memória pública e discurso oficial: visões da época salazarista na obra de Irene Lisboa, José Saramago e Mário Cláudio. Discursos, n. 13, out. 1996. 